\title{
A Study on Wearable Gestural Interface - A SixthSense Technology
}

\author{
Rakesh D. Desale ${ }^{1}$, Vandana S. Ahire ${ }^{2}$ \\ ${ }^{\text {I}(D e p a r t m e n t ~ o f ~ C o m p u t e r ~ E n g i n e e r i n g, ~ S S V P S ' s ~ B S ~ D e o r e ~ P o l y t e c h n i c, ~ D h u l e ~[M . S .], ~ I n d i a) ~}$ \\ ${ }^{2}$ (Department of Computer Engineering, SES's Polytechnic, Dhule [M.S.], India)
}

\begin{abstract}
SixthSense technology is a wearable gestural interface that links the physical world around us with digital information and allows us to use our natural hand gestures to communicate with the digital information. SixthSense Technology is comprised of mini-projector which is connected to a camera and a cell phone - that acts as a computer which is connected to Cloud. The information is stored on the web. SixthSense can also obey our natural hand gestures. The camera senses objects around us immediately, with the micro-projector spreads the information on any surface, including the object itself or hand. There are number of applications of the device, it is portable and easy to carry as we can wear it in our neck.
\end{abstract}

Keywords - Camera, Color Markers, Mirror, Mobile Phone, Pocket Projector

\section{INTRODUCTION}

When something, someone or someplace [16] is encountered, we use our five natural senses and these are eyes, ears, nose, tongue, and body to recognize the information about it. The information that was recognized by these five senses helps us to make decisions and based on this, we take the right actions. But there is also some kind of information which cannot be naturally recognized by our five senses namely the data, information and knowledge that human beings has gather about everything and is all time available online. This useful information can help us to make the right decision.

Now a day size of computing devices are greatly reduced which permits us to carry these small size computing devices in our pockets. These computing devices connect us continually to the digital world and most important thing to notice that there is no connection between our interactions with the physical world and our digital device. The information is kept in traditionally on to the paper or digitally on a screen. SixthSense [16] technology is used to bridges this gap, which brings incorporeal, digital information out into [16] the corporeal world, and permits us to communicate with this information via our natural hand gestures.

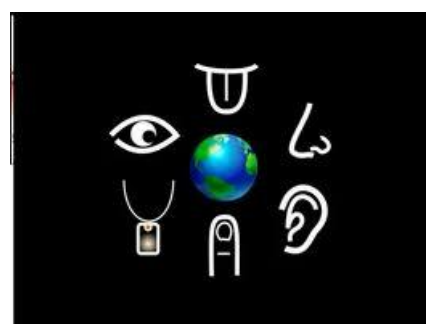

Fig. 1: Six Senses

SixthSense [16] is a wearable gestural interface device which was originally developed by Pranav Mistry, currently a research assistant and a PhD candidate at MIT Media Lab [22]. Before joining to MIT he was working as a UX Researcher with Microsoft [22]. He received his Master in Media Arts and Sciences from MIT and Master of Design from IIT Bombay. He has completed [22] his bachelors' degree in Computer Science and Engineering. He is originally from Palanpur, situated in northern Gujarat in India.

\section{Prototype}

The SixthSense technology also called as a wearable gestural interface made up of a pocket projector [16], a mirror [16], color markers, a smart phone and a camera. These hardware components are linked in a pendant like mobile wearable device. The projector and camera are connected to the mobile computing device. 


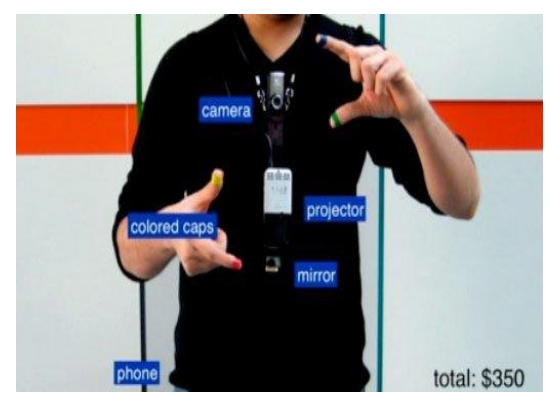

Fig. 2: SixthSense Prototype Design

We can consider Sixth Sense Technology as a combination of computer and smart phone. It works as the device associated to it is fixed or attach at an appropriate angle around the neck of a person and thus the projection starts by means of the micro projector attached to the device. This means, we can act as a moving computer in ourselves and our fingers are working just like a keyboard and mouse.

This SixthSense setup was built from a battery-powered 3M projector, with a mirror attached to it and, an ordinary webcam. All these devices are connected to an internet-enabled smart phone. According to Pranav Mistry the setup costs less than $\$ 350$, permits user to display information from the phone to any surface like on the walls, on the body of another person or even on our hand.

Mistry wear the device on a lanyard around his neck, with four color Marker caps red, blue, green and yellow on four fingers that helps the camera to distinguish between four fingers and sense his hand gestures with software developed by Pranav Mistry.

\section{WORKING}

As we now know that the SixthSense prototype is made up of hardware components that are linked in a pendant like mobile wearable devices. These devices are a pocket projector [16], a mirror [16], color markers, a mobile (smart) phone and a camera. Now let us see the working of each device in short.

\section{Projector}

The projector uses different interfaces like walls, surfaces and physical objects around us to [16] projects the visual information. The projector consists of a battery which has 3 hours of life. A very small LED projector displays the data sent from the smart phone on any surface in view-object, wall or person.

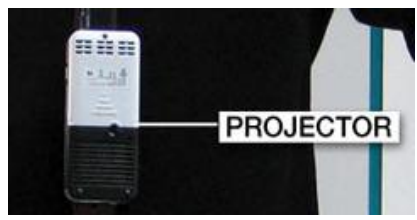

Fig. 3: Pocket Projector

\section{Camera}

The camera identifies and tracks user's hand gestures and physical objects around it by using computervision based techniques. The camera sends the data to a smart phone for further processing. The video stream data that is captured by the camera is processed by the software program. The program tracks the locations of the visual tracking fiducials (colored markers) at the tip of the user's fingers using the simple computer-vision techniques. In short we can say that the camera forms a digital eye which connects to the world of digital information.

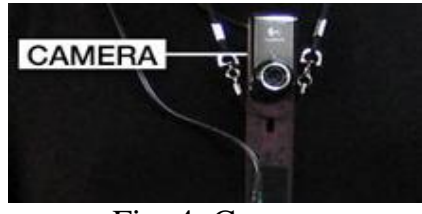

Fig. 4: Camera

\section{Color Markers}

The color markers also called as fiducials are placed at the tip of user's finger. There are four different types of colored markers like red, yellow green and blue. These different color tapes help the webcam to recognize the hand gestures. The movements and arrangements [16] of color markers are translated into gestures 
that can act as interaction instructions for the projected application interfaces. The maximum number of tracked fingers is only constrained by the number of unique fiducials. Because of this SixthSense also supports multitouch and multi-user interaction.

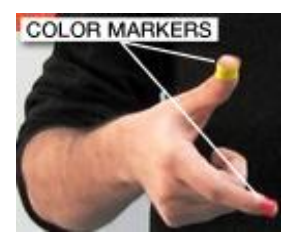

Fig. 5: Color Markers

\section{Mirror}

The use of mirror is important as the projector dangles pointing downwards from the neck. The mirror reflects the image on to a desire surface. Thus the digital image is freed from its restriction and placed in the physical world.

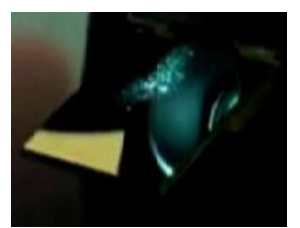

Fig. 6: Mirror

\section{Smart Phone}

The web enabled smart phone processes the data send by the camera. With help of the colored markers placed at the finger tips, the smart phone searches the web and interprets the hand gestures.

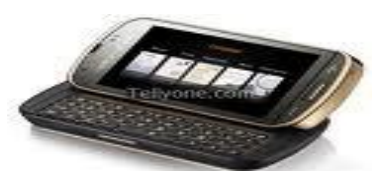

Fig. 7: Smart Phone

The overall working of the sixth sense technology is well understood by the following Fig:

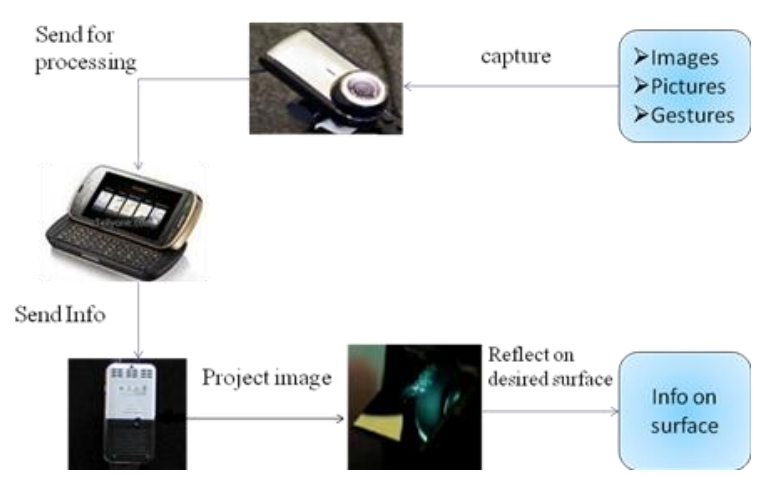

Fig. 8: Overall Working of Sixth Sense Technology

\section{RELATED TECHNOLOGIES}

There are following some technologies that are related to the sixth sense technology.

\section{Augmented Reality}

It is a term for a live direct or indirect view of a physical real world environment whose elements are linked by virtual computer generated imagery [23]. 


\section{Gesture Recognition} algorithms.

It is a language technology in computer science that interprets human gestures via mathematical

\section{Computer Vision} machines.

In Computer vision technology, the necessary information is interpreted / extracted from an image by

\section{Radio Frequency Identification}

Radio Frequency Identification is an electronic tagging technology [23] that permits the tracking, detection of tags and consequently the objects that they are attached to.

\section{APPLications}

There are number of applications of SixthSense technology that shows the usefulness [16], viability [16] and flexibility [16] of the system. Let's see one by one.

\section{Make a Call}

We can use SixthSense to display a virtual keypad on our hand, and then use that virtual keypad to make a call. There is no need of mobile device, simply type the number with our palm that acts as the virtual keypad. The keys will come up on the fingers. We can use the fingers of other hand to type the number and call.

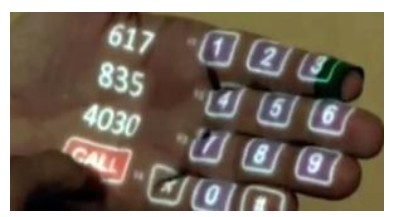

\section{Call Up a Map}

Fig. 9: Make a Call

The map application allow the user to navigate a map that displayed on a nearby surface by using our hand gestures, which is similar to the gestures supported by Multi-Touch based systems, permitting the user to zoom in, zoom out or pan using intuitive hand movements.

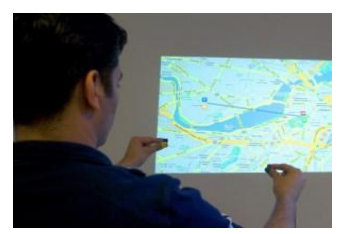

Fig. 10: Call a Map

\section{Check the Time}

The act of moving the limbs of drawing a circle on the user's wrist displays an analog watch. The computer recognizes the gesture, keeps track of the red marker cap and gives command to projector to display the image of a watch onto his wrist.

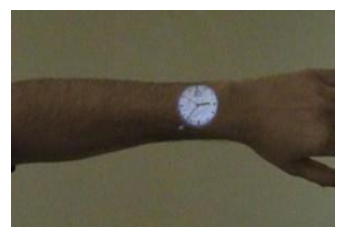

Fig. 11: Wrist Watch

\section{Create Multimedia Reading Experiences}

The SixthSense [16] system also links the physical objects that the user is communicating with by displaying more information about these objects projected on them. For example, a newspaper shows live video news on a regular piece of paper. 


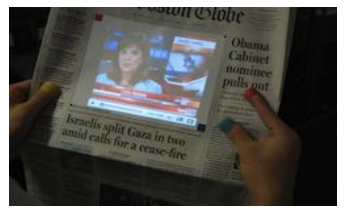

Fig. 12: Video in News Paper

\section{Drawing Applications}

The drawing application allows the user to draw on any surface by simply tracking the fingertip movements of the user's index finger.

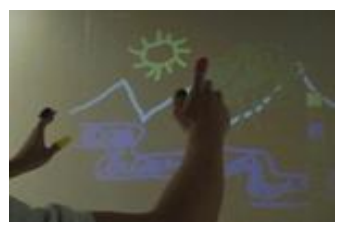

Fig. 13: Drawing

\section{Zooming Features}

We can zoom in or zoom out using features our intuitive hand movements.

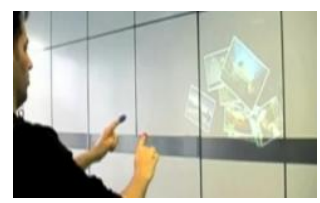

Fig. 14 (a): Zoom In

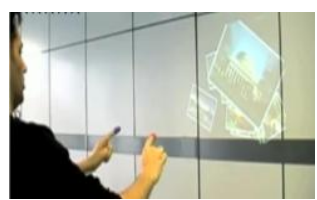

Fig. 14 (b): Zoom Out

\section{Get Product Information}

SixthSense uses image / marker recognition technology to sense products we pick up, and feeds us information on those products. For example, if we are trying to shop "green" and are looking for paper towels with the least amount of bleach in them, the system will scan the product [23] we pick up off the shelf and gives us guidance on whether this product is a good choice for us.

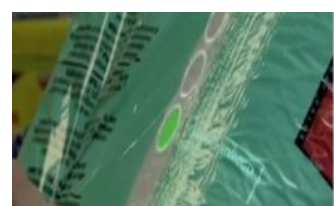

Fig. 15: Product Information

\section{Get Book Information}

The system displays Amazon ratings on the book, reviews and other relevant information.

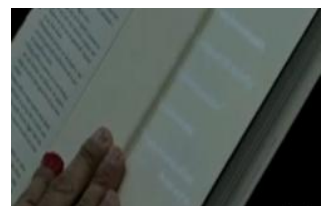

Fig. 16: Book Information

\section{Get Flight Updates} has changed.

The system recognizes boarding pass and let you know whether your flight is on time and if the gate 


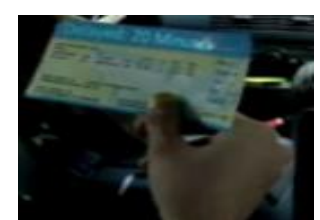

Fig. 17: Flight Updates

\section{Feed Information on People}

The system will display information about a person on another person's body such as what they do, where they work, and so on.

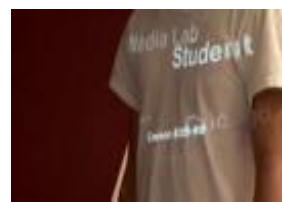

Fig. 18: Information on People

\section{Take Pictures}

If we adjust our index fingers and thumbs into a square in such a way that the frame is formed, the system will capture a photo. After capturing the desired number of photos, we can display them onto any surface, and use gestures to sort through the photos, and organize and resize them.
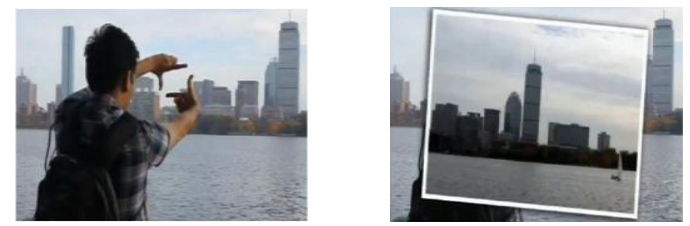

Fig. 19: Take Pictures

\section{Conclusion}

The Sixth Sense technology will remove the tedious task of carrying our laptops or any other devices which are very heavy. All we have to do is just wear the device which is a pendant shaped. It's light and easy to carry and easy access to any information. The inventor is now trying to make out a 3-D interface with the help of this device. This gives access to the information about the things in the environment and enables the new kind of interactions between the real world and the world of data. Although the reduced sized computing devices permits us to carry computers in our pockets, the thing to notice that there is no link between the digital devices that we carry with us and our communications with the physical world, and our speech in an efficient level. The main advantage of this technology is that it is portable, its connectedness between the world and the information as speech. It's less cost and the data can be accessed from the machine directly in real time. It can also be said as an open source technology.

\section{REFERENCES}

[1] Communication and Computational Intelligence (INCOCCI), 2010 International Conference on 27-29 Dec. 2010, 336-339, Erode, INSPEC Accession Number: 11887446, Current Version: 24 March 2011.

[2] Intelligent Agent Technology, 2006. IAT'06. IEEE/WIC/ACM International Conference on 18-22 Dec. 2006, pp 191-194 Hong Kong, ISBN: 0-7695-2748-5, INSPEC Accession Number: 10208238 Digital Object Identifier: 10.1109/IAT.2006.111.

[3] Steve Mann with Hal Niedzviecki, "Cyborg: Digital Destiny and Human Possibility in the Age of the Wearable Computer", ISBN 0385658257 (Hardcover), Random House Inc, 304 pages, 2001.

[4] John Wiley and Sons, Intelligent Image Processing, pp. 384,02001NOV02, ISBN 0-471-40637-6 sixthsense, Pranav Mistry.

[5] Aastha, Rashmi, Sakshi Bhatia and Geeta Rani, "Sensing the Sixth Sense Technology", International Journal of Information Technology and Knowledge Management January-June 2012, Volume 5, No. 1, pp. 201-204

[6] S. Sadhana Rao, "Sixth Sense Technology", Proceedings of the International Conference on Communication and Computational Intelligence - 2010, Kongu Engineering College, Perundurai, Erode, T.N.,India.27 - 29 December,2010.pp.336-339.

[7] Amit Kumar Gupta and Mohd Shahid, "The Sixth Sense Technology", Proceedings of the 5th National Conference; INDIACom2011 Computing For Nation Development, March 10 - 11, 2011, Bharati Vidyapeeth's Institute of Computer Applications and Management, New Delhi

[8] P. Mistry, P. Maes. "SixthSense - A Wearable Gestural Interface". In the Proceedings of SIGGRAPH Asia 2009, Sketch. Yokohama, Japan. 2009

[9] P. Mistry, P. Maes. "SixthSense - A Wearable Gestural Interface". In the Proceedings of SIGGRAPH Asia 2009, Emerging Technologies. Yokohama, Japan. 2009

[10] P. Mistry, P. Maes, L. Chang. "WUW - Wear Ur World - A Wearable Gestural Interface". In the CHI '09 extended abstracts on Human factors in computing systems. Boston, USA. 2009 
[11] P. Mistry. "The thrilling potential of SixthSense technology". TEDIndia 2009. Mysore, India 2009

[12] P. Maes, P. Mistry. Unveiling the "Sixth Sense", game-changing wearable tech. TED 2009. Long Beach, CA, USA 2009

[13] http://www.ted.com/talkspranav_mistry_the_thrilling_potential_of_sixthsense_technology.html TED Talks -Pranav Mistry: The thrilling potential of SixthSense technology

[14] http://boingboing.net/2009/11/12/sixthsense-technology.html

[15] http://theviewspaper.net/sixth-sense-technology-will-revolutionise-the world/

[16] http://www.pranavmistry.com/projects/sixthsense/

[17] http://lucasrichter.wordpress.com/2009/03/13/pattie-maes-sixth-sensetechnology-whats-stopping-this/

[18] CNet News: MIT's 6th Sense device could trump Apple's multitouch

[19] New York Times - At TED, Virtual Worlds Collide With Reality

[20] “2009 Young Innovators Under 35: Pranav Mistry, 28”. Technology Review, 2009. Retrieved August 14, 2011.

[21] http://code.google.com/p/sixthsense/

[22] http://www.pranavmistry.com

[23] http://www.authorstream.com/Presentation/Karankinng-1368341-sixth-sense-technology-report/ 